\title{
Effect of Single and Duplex Stage Heat Treatment on the Microstructure and Mechanical Properties of Cast Ti-6Al-4V Alloy
}

\author{
Reham Reda $\cdot$ Adel Nofal $\cdot$ Abdel-Hamid Hussein
}

Received: 23 July 2013/Revised: 19 September 2013/Accepted: 14 October 2013/Published online: 15 November 2013

(C) Springer Science+Business Media New York and ASM International 2013

\begin{abstract}
The effect of single and duplex stage heat treatment on the microstructure and mechanical properties of cast Ti-6Al-4V alloy was studied. The single stage heat treatment (SSHT) involved solution annealing at $935^{\circ} \mathrm{C}$ for $10 \mathrm{~min}$ followed by water quenching, while the duplex stage heat treatment (DSHT) involved solution annealing at $935^{\circ} \mathrm{C}$ for $10 \mathrm{~min}$, furnace cooling to 600 and $700{ }^{\circ} \mathrm{C}$, followed by isothermal holding for $30 \mathrm{~min}$ and subsequent water quenching. The properties characterization was conducted using microstructure investigation along with tensile, hardness, and Charpy impact tests. The impact fracture surfaces were observed using Scanning Electron Microscope. After SSHT, an increase in the tensile strength and hardness at the expense of the tensile elongation and impact toughness was recorded as compared with the as-cast alloy. This is attributed to the formation of a brittle $\alpha^{\prime}$ martensite phase in the microstructure after quenching from $935^{\circ} \mathrm{C}$. On the other hand, DSHT enhances the percent elongation and impact toughness over the as-cast alloy and SSHT. The formation of $\alpha^{\prime}$ martensite-free microstructure as well as controlling the composition of the different microstructural constituents during DSHT optimizes the mechanical properties.
\end{abstract}

Keywords Single/duplex stage heat treatment . Cast Ti-6Al-4V alloy · Microstructure $\cdot$ Tensile strength $\cdot$ Tensile elongation $\cdot$ Hardness $\cdot$ Impact toughness $\cdot$ Fracture surface

R. Reda $(\bowtie) \cdot$ A. Nofal

Central Metallurgical R\&D Institute, P.O. Box 87, Helwan,

Egypt

e-mail: Metallurgist_reham@yahoo.com

A.-H. Hussein

Faculty of Engineering, Cairo University, Giza, Egypt

\section{Introduction}

The requirements for outstanding mechanical properties can justify the growing use of Ti-alloys in applications such as the aerospace, automotive, medical, marine, chemical industries, and sporting goods sectors [1-8]. Due to the significant raw-material costs, the manufacture of near net-shape of Ti-alloy components is an attractive field. Casting technologies enable manufacturing of complex shapes and large parts $[1-3,5,8]$, such as: cast frames for aircraft engines, compressor casings, cast fan frames, exhaust gas pipes of auxiliary gas turbines, connecting rods, intake and outlet valves, and rim screws. Titanium castings have been used also in biomedical and dental applications, e.g., cast hip joint stems as well as for crowns and bridges. Heat treatment is used for improving the properties of the casting parts through microstructural control. The properties of Ti-alloys can be significantly changed through processing as well as heat treatment $[1,4$, $6,8-12]$.

The most commonly used Ti-alloy is the two phase $(\alpha+\beta)$ alloy, Ti-6Al-4V. The existence of the $\alpha / \beta$ transformation means that a variety of microstructures and property combinations can be achieved in the alloy through heat treatment, thus permitting the adaptation of properties to specific applications $[8,9]$. For example, solution treatment in $\beta$ or at high temperature in $\alpha+\beta$ range, followed by aging for long periods, increases tensile strength and hardness at the expense of tensile elongation and impact toughness [1, 8]. After such heat treatment, the alloy shows brittle failure when subject to impact. On the other hand, annealing at low temperature in $\alpha+\beta$ range for long time followed by furnace or air cooling enhances the tensile elongation and impact toughness at the expense of tensile strength and hardness [12]. Therefore, the objective of this work is to 
examine the effect of different heat treatment cycles, aiming at optimizing the mechanical properties in order to improve the performance of the $\mathrm{Ti}-6 \mathrm{Al}-4 \mathrm{~V}$-casting parts in their applications. This aim was achieved through conducting a number of heat treatment cycles and characterizing the properties of the alloy after these treatments using microstructural investigation in addition to tensile, hardness, and Charpy impact tests. The fracture surfaces of the impact specimens were also investigated.

\section{Experimental Work}

The material used in this study was cast Ti-6Al-4V alloy. The chemical composition of the studied alloy is shown in Table 1.

Heat treatment cycles conducted throughout this study are shown in Fig. 1. The single stage heat treatment (SSHT) involved heating the samples to $935^{\circ} \mathrm{C}$, and isothermal holding for $10 \mathrm{~min}$, followed by water quenching. The duplex stage heat treatment cycles (DSHT) involved furnace cooling from $935^{\circ} \mathrm{C}$, after 10 min holding, to 600 and $700{ }^{\circ} \mathrm{C}$ followed by isothermal holding for $30 \mathrm{~min}$, before water quenching down to room temperature. Computerized furnace with a controlled atmosphere was used for heat treatment. Heat treatments were carried out in an argon environment at a flow rate of $200 \mathrm{CFH}$ and 1 bar.

The as-cast and heat-treated specimens were prepared by standard metallographic techniques, which consist of polishing and etching in an etchant composed of $10 \% \mathrm{HNO}_{3}, 5 \%$ $\mathrm{HF}$, and $85 \%$ distilled water. After etching, the specimens were examined with an optical microscope and using backscattered electron imaging in a scanning electron microscope along with energy-dispersive spectrometry (EDS) to analyze the different phases. X-ray diffraction analysis with $\mathrm{CuK}_{\alpha}$ radiation as well as image analysis was used for quantitative measurement of the volume fraction of the different phases.

After heat treatment and prior to mechanical testing, specimens were hand-ground progressively to achieve a smooth surface. The surface oxide layer formed during the heat treatments was completely removed by polishing.

Tensile specimens were prepared in accordance with ASTM E8, with a specimen length of $130 \mathrm{~mm}$, gage length of $30 \mathrm{~mm}$, and gage diameter of $6 \mathrm{~mm}$. Uniaxial tensile tests were carried out at room temperature at a strain rate of $0.5 \mathrm{~mm} / \mathrm{min}$.

Standard Charpy V-notch impact specimens were prepared in accordance with ASTME23 standard specifications. Charpy impact tests were done using a 150-J capacity machine at room temperature. $5 \times \times 55 \mathrm{~mm}^{3}$ Charpy

Table 1 Chemical composition of the studied alloy

\begin{tabular}{lllllllll}
\hline Element & $\mathrm{Al}$ & $\mathrm{V}$ & $\mathrm{Fe}$ & $\mathrm{C}$ & $\mathrm{O}$ & $\mathrm{N}$ & $\mathrm{H}$ & $\mathrm{Ti}$ \\
\hline wt. $\%$ & 5.851 & 4.2 & 0.2 & 0.1 & 0.2 & 0.00158 & 0.00531 & Balance \\
\hline
\end{tabular}

Fig. 1 Single and duplex stage heat treatment cycles

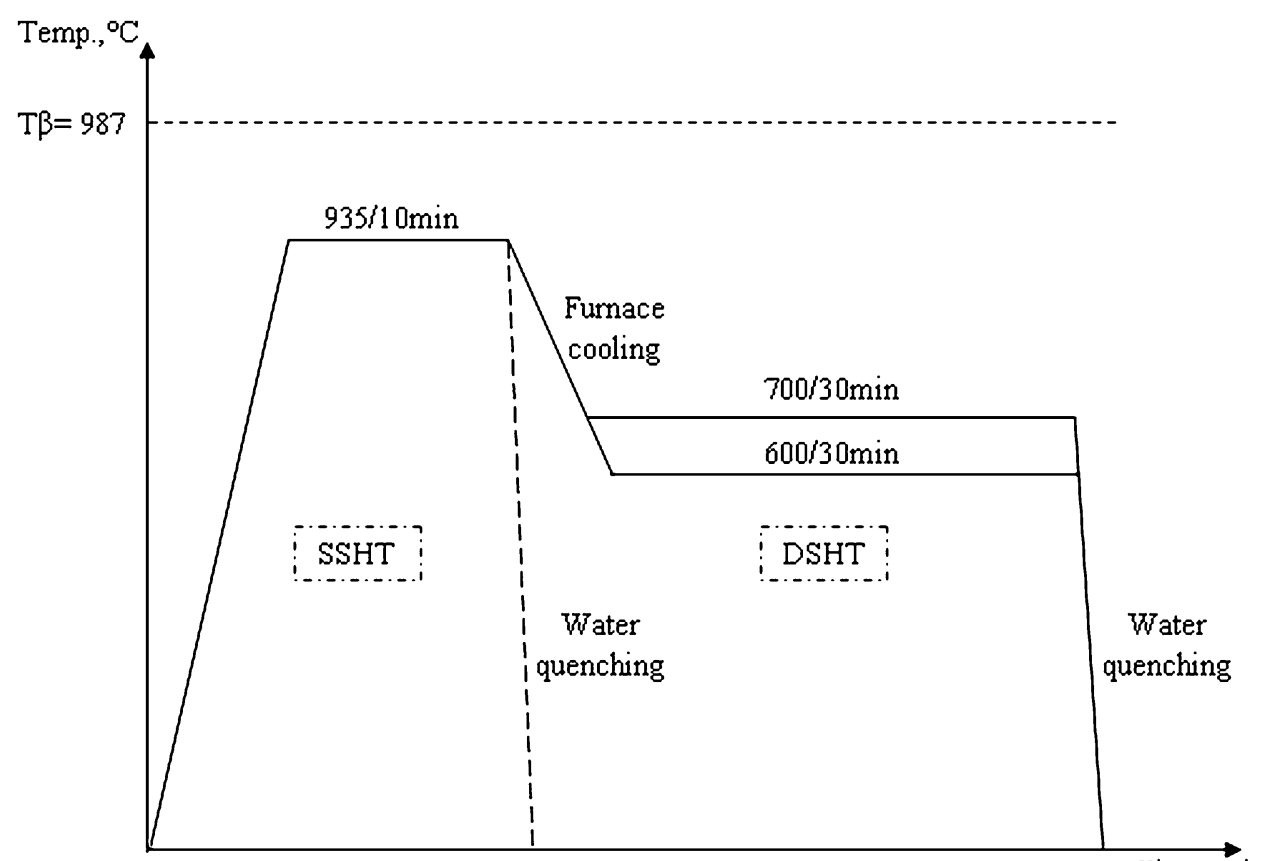

Time, $\min$ 
specimens with a $45^{\circ} \mathrm{V}$ notch and $2 \mathrm{~mm}$ deep with a 0.25 $\mathrm{mm}$ root radius were used. After impact testing, fracture surfaces of the notched specimens were carefully observed by scanning electron microscope (SEM) to investigate the fracture mode and crack propagation behavior.

The average bulk Vickers hardness $\left(\mathrm{Hv}_{30}\right)$ of the specimens was measured using an applied load of $30 \mathrm{~kg}$, loading time of $15 \mathrm{~s}$ and $100 \mu \mathrm{m} / \mathrm{s}$ indenter speed, according to ASTM E92. Six readings were taken on each sample and the average of them is reported.

\section{Results and Discussion}

Microstructural Investigation

Microstructure of the as-cast Ti-6Al-4V alloy is shown in Fig. 2. The bright regions in the optical micrograph (Fig. 2a) correspond to $\alpha$-phase, forming a typical Widmansttaten structure, whereas thin dark regions between
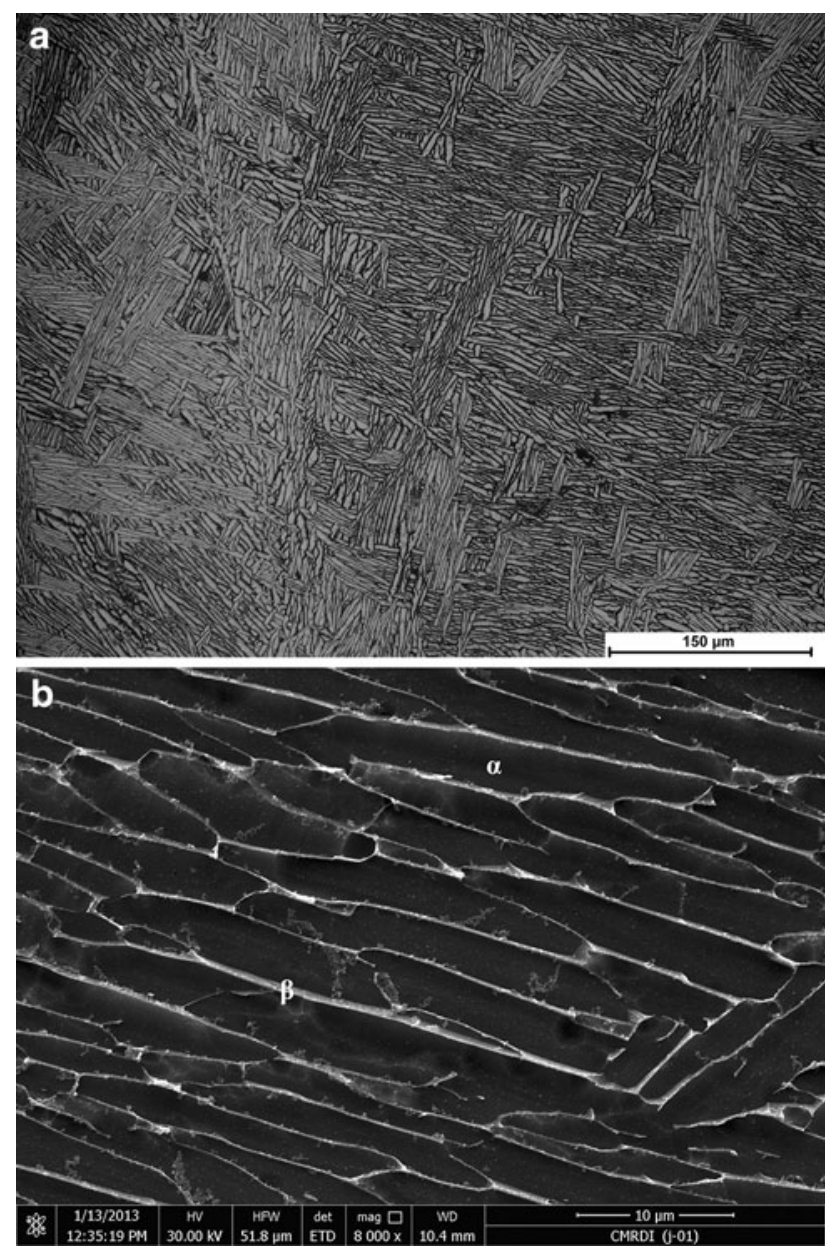

Fig. 2 Microstructure of the as-cast Ti-6Al-4V alloy: (a) optical micrograph shows thin areas of dark $\beta$-phase between bright lamellae $\alpha$-phase $(\times 200)$; and (b) backscattered SEM image; light and dark regions are $\beta$ - and $\alpha$-phases, respectively
Table 2 Volume fractions (\%) of the different phases

\begin{tabular}{llll}
\hline Conditions & \multicolumn{2}{l}{ Phases } & $\% \alpha^{\prime}$ \\
\cline { 2 - 4 } & $\% \beta$ & $\% \alpha$ & - \\
\hline As-cast & 10 & 90 & 44 \\
SSHT & 15 & 41 & - \\
DSHT/600 ${ }^{\circ} \mathrm{C}$ & 14 & 88 & - \\
DSHT/700 ${ }^{\circ} \mathrm{C}$ & 19 & 80 & \\
\hline
\end{tabular}
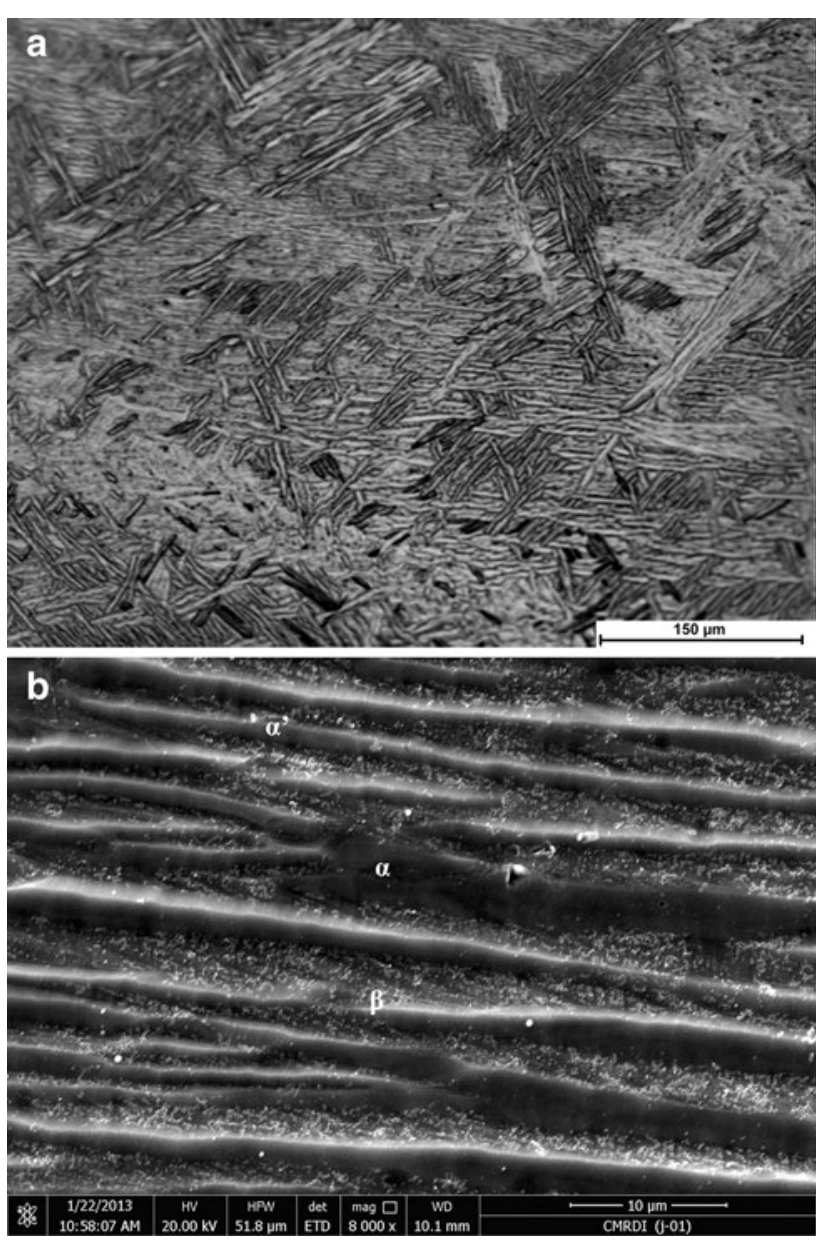

Fig. 3 Microstructure of Ti-6Al-4V alloy after SSHT: (a) optical micrograph shows a microstructure consisting of bright $\alpha$-phase, gray $\beta$-phase, and black $\alpha^{\prime}$-martensite phase $(\times 200)$, and (b) backscattered SEM image reveals the acicular morphology of $\alpha^{\prime}$-martensite phase along with bright retained $\beta$ - in $\alpha$-phase matrix

$\alpha$-plates are $\beta$-phase. In the Widmanstatten microstructure, $\alpha$-phase is formed along prior $\beta$-grain boundaries, and colonies of lath-type $\beta$ and $\alpha$ lamellar structure are present inside prior $\beta$ grains. In the backscattered SEM image (Fig. 2b), the bright areas represent $\beta$-phase and the dark regions are $\alpha$-phase. $\beta$-Phase was measured by XRD to be $10 \%$, as presented in Table 2 .

The $\alpha \rightarrow \beta$ transformation temperature for Ti-6Al-4V alloy used in this study was determined to be $987^{\circ} \mathrm{C}$ using 

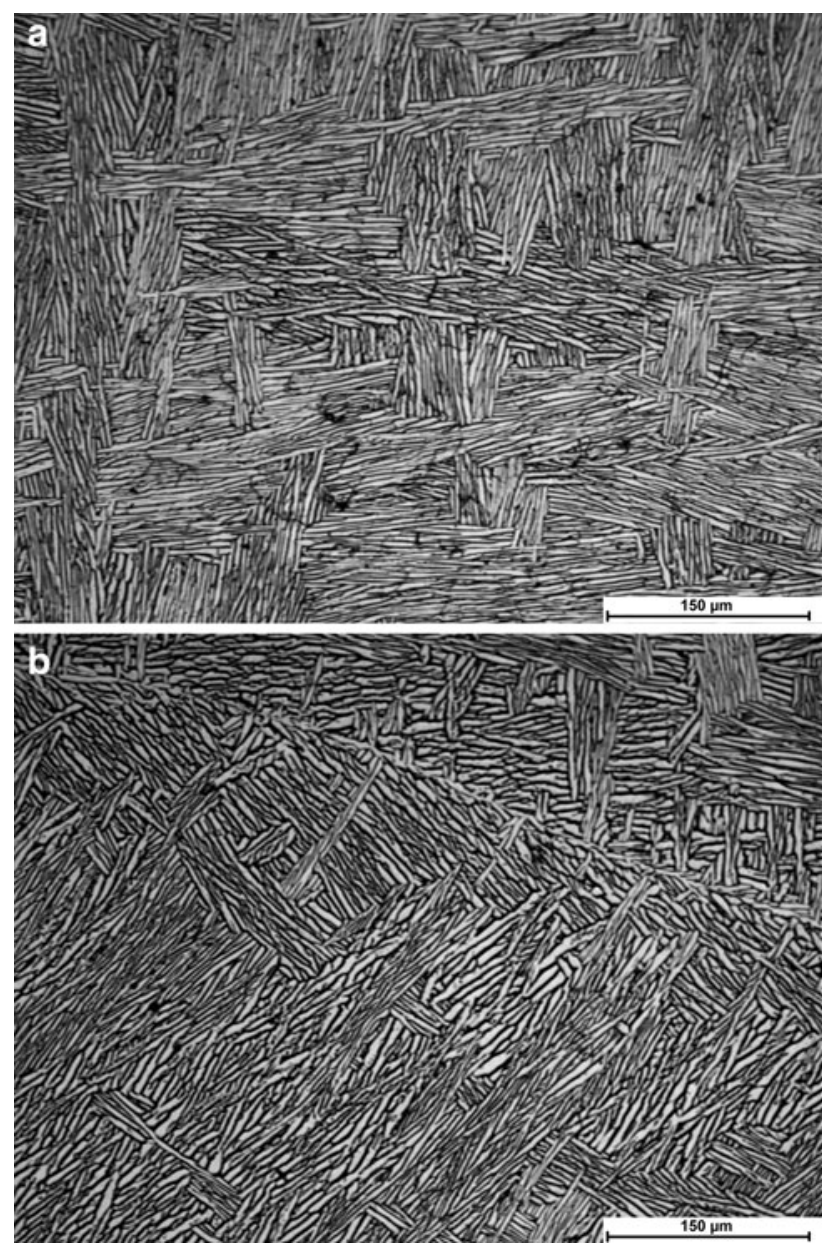

Fig. 4 Optical micrographs of Ti-6A1-4V alloy after DSHT at: (a) $600{ }^{\circ} \mathrm{C}$ and (b) $700{ }^{\circ} \mathrm{C}(\times 200)$

Table 3 Chemical composition (\%) of $\alpha$ - and $\beta$-phases after DSHT

\begin{tabular}{|c|c|c|c|c|c|c|}
\hline \multirow[t]{3}{*}{ Condition } & \multicolumn{6}{|c|}{ Phase } \\
\hline & \multicolumn{3}{|c|}{$\alpha$-phase } & \multicolumn{3}{|c|}{$\beta$-phase } \\
\hline & $\% \mathrm{~V}$ & $\% \mathrm{Al}$ & $\% \mathrm{Ti}$ & $\% \mathrm{~V}$ & $\% \mathrm{Al}$ & $\% \mathrm{Ti}$ \\
\hline $\mathrm{DSHT} / 600{ }^{\circ} \mathrm{C}$ & 0.86 & 7.48 & 91.67 & 9.25 & 4.84 & 85.9 \\
\hline $\mathrm{DSHT} / 700{ }^{\circ} \mathrm{C}$ & 0.36 & 7.79 & 91.84 & 7.32 & 5.07 & 87.58 \\
\hline
\end{tabular}

heat-flux differential scanning calorimetry (DSC). This result is in agreement with previous data $[1,4,6,8,11]$.

The microstructure of $\mathrm{Ti}-6 \mathrm{Al}-4 \mathrm{~V}$ alloy after single stage heat treatment (SSHT) from $935^{\circ} \mathrm{C}$ is shown in Fig. 3. Optical micrograph of the microstructure after SSHT (Fig. 3a) consists of a mixture of $\alpha^{\prime}$ martensite and $\beta$ structures with $\alpha$ plates formed inside and at prior $\beta$-grain boundaries. Table 2 presents the volume fraction of the different phases after SSHT. Many authors $[1,8,11]$ pointed out that the $\alpha$-phase cannot be differentiated from $\alpha^{\prime}$ martensite phase by $\mathrm{x}$-ray diffraction measurements because the inter-planar spacing in the two structures are nearly the same. Consequently, the obtained x-ray diffraction data can only confirm the presence of a stable $\beta$-phase in quantities high enough to be detected. Therefore, $\beta$-phase was determined using XRD analysis while the bright $\alpha$-phase was measured using image analysis and the remained $\alpha^{\prime}$ martensite phase was a rough estimation of the supplement equal to 100 . Backscattered SEM image of the alloy after SSHT (Fig. 3b) reveals the morphology of the acicular $\alpha^{\prime}$ martensite phase along with bright areas of the retained $\beta$-phase in a dark matrix of $\alpha$-phase. The presence of $\alpha^{\prime}$ martensite phase after quenching from high temperature in $\alpha+\beta$ range is widely reported by several authors $[1-4,6,8,11]$.

Microstructures after duplex stage heat treatment (DSHT) at 600 and $700{ }^{\circ} \mathrm{C}$ are shown in Fig. 4. In these conditions, the microstructure consists of $\alpha$ and $\beta$-phases. The microstructure after DSHT appears more homogenous compared with the as-cast condition. There is no $\alpha^{\prime}$ martensite phase formed after DSHT. Controlled cooling followed by isothermal holding at low temperature promotes the growth of $\alpha$ plates, thus enriching the $\beta$ phase with $\beta$ stabilizers. The enriched $\beta$-phase has a lower beta-transus (Ms) temperature and, hence, a lower tendency to transform to $\alpha^{\prime}$ so $\beta$-phase remains at room temperature as retained $\beta$ [13].

The microstructure after DSHT at $600{ }^{\circ} \mathrm{C}$ (Fig. 4a) contains lower amounts of retained $\beta$-phase than at $700{ }^{\circ} \mathrm{C}$ (Fig. 4b), as reported in Table 2. This is in agreement with previous results $[2,4,11]$ which stated that as the solution treatment temperature in $\alpha+\beta$ range decreases, the $\alpha$ phase fraction increases at the expense of $\beta$-phase. On the other hand, $\beta$-stabilizer concentration $(\mathrm{V} \%)$ in $\beta$-phase

Table 4 Mechanical properties of Ti-6Al-4V alloy

\begin{tabular}{|c|c|c|c|c|c|}
\hline \multirow[t]{2}{*}{ Condition } & \multicolumn{5}{|l|}{ Property } \\
\hline & UTS (MPa) & Yield Strength (MPa) & Elongation \% & Hardness (Hv30) & Impact toughness $(\mathrm{J})$ \\
\hline As-cast & 900 & 837 & 6.8 & 317 & 11 \\
\hline SSHT & 1120 & 1072 & 4.85 & 385 & 8 \\
\hline $\mathrm{DSHT} / 600{ }^{\circ} \mathrm{C}$ & 894 & 829 & 10.4 & 321 & 12 \\
\hline $\mathrm{DSHT} / 700{ }^{\circ} \mathrm{C}$ & 922 & 810 & 7 & 331 & 9 \\
\hline
\end{tabular}


increases with decreasing temperature. Table 3 presents the composition of $\alpha$ - and $\beta$-phases after DSHT. As illustrated, $\% \mathrm{~V}$ is higher after DSHT at 600 than at $700{ }^{\circ} \mathrm{C}$.

\section{Mechanical Properties}

The effect of different heat treatment cycles on the mechanical properties of Ti-6Al-4V alloys is presented in Table 4 . The tensile strength increased after SSHT with a reduction in the tensile elongation compared with the as-cast alloy. This is attributed to the formation of a brittle $\alpha^{\prime}$ martensite phase after quenching from $935{ }^{\circ} \mathrm{C}$. After DSHT at $600{ }^{\circ} \mathrm{C}$, the tensile strength slightly decreases with an increase in the tensile elongation compared with the as-cast alloy, while DSHT at $700{ }^{\circ} \mathrm{C}$ slightly increases the ultimate tensile strength as well as tensile elongation over the as-cast alloy.

Improvement in the tensile elongation after DSHT is attributed to the formation of $\alpha^{\prime}$ martensite free homogenous microstructure. The increase in the ultimate tensile strength after DSHT at $700{ }^{\circ} \mathrm{C}$ over $600{ }^{\circ} \mathrm{C}$ is due to the higher volume fraction of retained $\beta$-phase at higher temperature, as presented in Table 2. This result is in agreement with Rhodes et al. [10] who stated that the presence of the retained $\beta$-phase in the microstructure of Ti-6Al-4V alloy improve its mechanical properties. Rhodes et al. [10] reported also that $\beta$-phase enhances the strength by solid solution strengthening by vanadium. Therefore, the main strengthening mechanism in DSHT conditions is the solid solution strengthening effect of $\beta$-phase.

Yield strength value after DSHT at $700{ }^{\circ} \mathrm{C}$ is lower than at $600{ }^{\circ} \mathrm{C}$ in contrast to the increased value of ultimate tensile strength. This can be interpreted by the higher $\mathrm{V}$ content in $\beta$-phase after DSHT at $600{ }^{\circ} \mathrm{C}$ over $700{ }^{\circ} \mathrm{C}$. Rhodes et al. [10] reported that the increase in $\mathrm{V}$ content of $\beta$-phase enhances the yield strength.

Table 4 presents also the effect of SSHT and DSHT on the hardness values of Ti-6Al-4V alloy. The highest hardness value is associated with the formation of $\alpha^{\prime}$ martensite phase after SSHT. DSHT enhances the hardness values compared with the as-cast alloy. Hardness is higher after DSHT at $700{ }^{\circ} \mathrm{C}$ than at $600{ }^{\circ} \mathrm{C}$. This is attributed to the higher volume fraction of $\beta$-phase at $700{ }^{\circ} \mathrm{C}$. $\beta$-Phase increases the hardness by solid solution strengthening effect of vanadium.

The effect of SSHT and DSHT on the Charpy impact toughness is reported in Table 4. The impact toughness results change in the same trend as tensile elongation results. The impact toughness after SSHT decreases compared with as-cast alloy; as a result of formation of brittle $\alpha^{\prime}$ martensite phase after quenching from $935{ }^{\circ} \mathrm{C}$. On the other hand, the impact toughness increases after DSHT at $600{ }^{\circ} \mathrm{C}$ and decreases after DSHT at $700{ }^{\circ} \mathrm{C}$. This is attributed to the lower volume fraction of the strengthening phase, i.e., the retained $\beta$-phase, at $600{ }^{\circ} \mathrm{C}$.
Fractography

Figure 5 shows SEM fractographs of some specimens after impact testing. The fracture surface of the as-cast microstructure (Fig. 5a) was a mixed mode fracture consisting primarily of ductile dimples with some cleavage fracture.
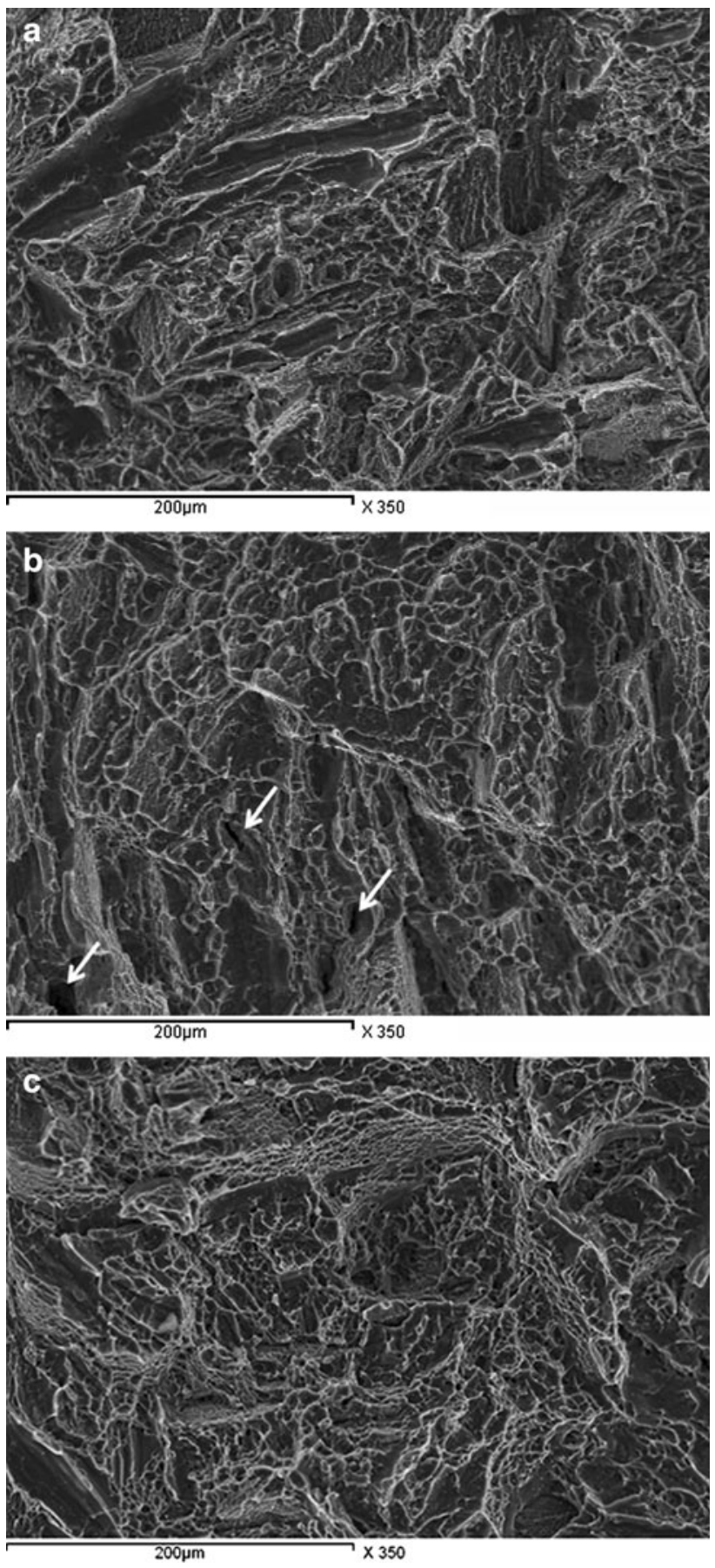

Fig. 5 SEM micrographs reveal the fracture surface of Ti-6A1-4V alloy: (a) cast alloy (b) SSHT; arrows refer to the microcracks, and (c) DSHT/600 ${ }^{\circ} \mathrm{C}$ 
After SSHT, the amount of dimples decreased as compared with the as-cast structure, in addition to the presence of many microcracks (arrowed), as shown in Fig. 5b. This indicates that the brittle $\alpha^{\prime}$ martensite phase plays a role in the fracture behavior of SSHT samples.

For the duplex condition (DSHT/600 ${ }^{\circ} \mathrm{C}$ ), the energy consumption is based on both the comparatively ductile behavior of the homogenous microstructure as well as crack deflection along and within the lamellar grains, see Fig. 5c. The fracture surface reveals more homogenous distribution of finer dimples after DSHT. The Widmanstatten structure has large colonies with a lamellar structure consisting of $\alpha$-phase with strong $\beta$-phase, and these colonies have different lamellar directions. Crack branching and zigzaging occurred when cracks propagated, which increased resistance to crack propagation and increased the toughness, compared to the SSHT samples [13].

\section{Conclusion}

The effect of SSHT and DSHT on the mechanical properties of the as-cast Ti-6Al-4V alloy was studied.

1. After SSHT, an increase in the tensile strength and hardness occurs at the expense of the tensile elongation and impact toughness compared with the as-cast alloy. This is attributed to formation of a brittle $\alpha^{\prime}$ martensite phase after quenching from $935^{\circ} \mathrm{C}$.

2. There is an improvement in the tensile elongation after DSHT over the as-cast alloy which may be attributed to the formation of homogenous microstructure free from brittle $\alpha^{\prime}$ martensite phase after quenching from low temperature $\left(600\right.$ and $\left.700{ }^{\circ} \mathrm{C}\right)$.

3. The increase in the ultimate tensile strength after DSHT at $700{ }^{\circ} \mathrm{C}$ over $600{ }^{\circ} \mathrm{C}$ is due to the higher volume fraction of retained $\beta$-phase at higher temperature that causes soli-strengthening effect. On the other hand, yield strength after DSHT is lower at $700{ }^{\circ} \mathrm{C}$ than at $600{ }^{\circ} \mathrm{C}$; this is attributed to the higher $\mathrm{V}$ content of the strengthening phase at $600{ }^{\circ} \mathrm{C}$.

4. DSHT enhances the hardness values. This indicates that higher fraction of retained $\beta$-phase after DSHT as compared with the as-cast alloy plays an important role in the alloy strengthening.
5. Fracture surface of the as-cast microstructure show mixed mode of fracture. Lower amount of dimples along with many microcracks characterize the fracture surface after SSHT. After DSHT, the fracture surface reveals more homogenous distribution of finer dimples.

\section{References}

1. M.T. Jovanovic, S. Tadic, S. Zec, Z. Miskovic, I. Bobic, The effect of annealing temperatures and cooling rates on microstructure and mechanical properties of investment cast Ti-6Al4V alloy. Mater. Des. 27, 192-199 (2006)

2. C. Leyens, M. Peters, Titanium and titanium alloys, fundamentals and applications (Wiley-VCH, Weinheim, 2003)

3. G. Lütjering, J.C. Williams, Titanium, 2nd edn. (Springer, Berlin, 2007)

4. L.W. Meyer, L. Krüger, K. Sommer, T. Halle, M. Hockauf, Dynamic strength and failure behavior of titanium alloy Ti-6Al$4 \mathrm{~V}$ for a variation of heat treatments. Mech. Time-Depend. Mater. 12, 237-247 (2008)

5. M. Bermingham, S. McDonald, M. Dargusch, D. StJohn, Microstructure of cast titanium alloys. Mater. Forum 31, 84-89 (2007)

6. B.D. Venkatesh, D.L. Chen, S.D. Bhole, Effect of heat treatment on mechanical properties of Ti-6Al-4V ELI alloy. Mater. Sci. Eng. A506, 117-124 (2009)

7. Jun. Cai, Fuguo. Li, Taiyin. Liu, Bo. Chen, Investigation of mechanical behavior of quenched Ti-6Al-4V alloy by microindentation. Mater. Charact. 62, 287-293 (2011)

8. R. Reda, A.A. Nofal, A.A. Hussein, Effect of quenching temperature on the mechanical properties of cast Ti-6Al-4V alloy. J. Metall. Eng. 2(1), 48-54 (2013)

9. S. Semiatin, S. Knisley, P. Fagin, F. Zhang, D. Barker, Microstructure evolution during $\alpha-\beta$ heat treatment of Ti-6Al-4V. Metall. Mater. Trans. 34A, 2377-2386 (2003)

10. C. Rhodes, N. Paton, The influence of $\alpha / \beta$ interface phase on tensile properties of Ti-6Al-4V. Metall. Trans. 10A, 1753-1758 (1979)

11. T. Morita, K. Hatsuoka, T. Iizuka, K. Kawasaki, Strengthening of Ti-6Al-4V alloy by short-time duplex heat treatment. Mater. Trans. 46(7), 1681-1686 (2005)

12. A. Corona, in Characterization of the relationship between the microstructure and tensile strength of annealed Ti-6Al-4V. Senior Project Report, California Polytechnic State University (2011)

13. D.G. Lee, S. Lee, Y. Lee, Effect of precipitates on damping capacity and mechanical properties of Ti-6Al-4V alloy. Mater. Sci. Eng. A486, 19-26 (2008) 